\title{
A Mobile Device Supported Blended Learning Approach for Postgraduate Students where Absenteeism from Classes had Previously been an Issue
}

\author{
Iain Carruthers-Jones, Human Resources and Organisational Behaviour, Business School
}

\begin{abstract}
While the students on a postgraduate course were reportedly motivated by the course, which was accredited by a professional body, there was a high level of absenteeism in earlier courses years. A blended learning approach was introduced which allowed the students to attend lectures and tutorials but also to access course material, listen to lecture-based podcasts, participate in chat room tutorials and use other resources, such as the library resources, at any time. To ensure a common technology platform, each student was issued with an iPad2. The blended learning approach and the availability of mobile devices gave flexibility to assist and support learning. Lessons learned included (1) that introducing the blended learning approach appeared to have a positive impact on academic results (2) traditional attendance measures became less relevant, (3) that students wanted to retain an amount of face to face time rather than go solely online and (4) that students vary in the enthusiasm with which they embrace the blended learning approach.
\end{abstract}

\section{Introduction}

In October 2010, the author took over responsibility for the delivery of the course titled Research Methods (INDU1008), which is part of the Masters Degree course in Human Resource Management. This course is run in the University of Greenwich Business School (UoGBS) through the Department of Human Resources and Organisational Behaviour (HROB). It has CIPD approval and has run for a number of years. It takes place in the autumn term of the academic year. The students have been required to attend lectures weekly on a Monday evening (18.00-21.00). They attend a separate course on a Wednesday evening; this second course is part of the Masters programme, as well.

On Monday evenings, the 18.00-21.00 time period was split into two parts with a short break of 15 minutes in the middle. The first 75 minutes comprised a lecture on the course topic of the week and the period 19.30-21.00 comprised a tutorial during which group work considered some practical case work issues that were related to topics that had been covered in the lecture.

\section{The Historical Background}

During the 2010-2011 academic year, the author became concerned about poor attendance on Monday evenings. Poor attendance took two forms; lateness and non-attendance. The former was very common. While the lecture always started at 18.00 typically there would be only three or four of the cohort of 15 present. Others would appear, usually out of breath, over the next hour. Attendance by 19.00 was usually about $65 \%$. 
Attendance was more of a challenge for some than for others. While some of the cohort were merely consistently late, others were frequently absent altogether. Some managed to attend only about 6 of the 11 sessions. One managed only 3 of the 11 .

The author's concern led to discussions with the students about the reasons for the lateness and absenteeism. All expressed a wish to regularly attend. However, all mentioned as well that there was a significant challenge for each of them since they were all professional people with significant responsibility. This often involved travel and participation in board or senior management level meetings. Several had family responsibilities as well. It was difficult to achieve a balance.

While all passed the course requirements, which included two written assignments, the range of scores was wide. Some achieved good scores and some clearly struggled. Those that struggled reported feeling disadvantaged by their own poor rate of attendance. It seemed regrettable to the author that these time-poor students had such difficulties. The resources provided for them comprised lectures, which many had difficulty attending, lectures notes (from the times they managed to attend), a set of PowerPoint slides from each lecture and a course handbook.

The author's reflection on ways to improve the situation for students was given urgency by his recognition that he himself faced a similar kind of challenge since he had a busy job, family responsibilities and he was attending a continuing professional development course, as well. This course provided, however, the key to solving the problem since it was a course to achieve a Certificate in Transformational Learning with Digital Technologies (Cert PD (TLDT)). This course involved meeting, over a two year period ( the academic years 20102012), with course tutors and doing most of the study work using an online, project based approach with the requirement to submit assignments each term. This course offered the opportunity to develop both a theoretical and practical understanding of the advantages and challenges involved in developing and delivering learning resources using digital technology.

\section{Literature Review}

The author reviewed recently published work with a view to consider using a blended learning approach with the INDU1008 course cohort for 2011-2012. It was anticipated that such an approach might provide a richer learning resource for the students as well as neutralise the attendance problem.

To begin with it was important for the author to achieve an understanding of what is meant by the term "blended learning". The variety of ways in which this term has been used is considerable. In order to move on from insisting on a position of theoretical purity, the position taken by the authors of the Australian Learning and Teaching Council (ALTC) was adopted. The authors of the ALTC Good Practice Report (Partridge et al., 2011) made it clear that in their opinion there is no single, collectively accepted definition of blended learning. In this case study report it has been used to describe teaching where there is an integration of face-to-face contact and online delivery. This approach marks a shift from passive to active learning for students; it is suggested that educators need to facilitate active learning. 
Briefly, the challenges of using a blended learning approach relate to issues faced by both the students and the teaching staff.

- It has been suggested that 'blended courses require a degree of self-motivation and independent learning which can be unfamiliar to students who have only experienced traditional face-to-face formats' (Gerbic \& Stacey, 2009, 299).

- From a faculty perspective, a major concern is the increased time commitment involved to develop appropriate materials, such as audio podcasts, for online delivery (Welker \& Berardino, 2005). They suggested that 'blended courses take longer to prepare and administer than their traditional counterparts.' (34).

- Research indicates that 'Faculty support and resources for course redesign, along with the development of new teaching and technology skills are also important factors in delivering successful blended courses' (Gerbic \& Stacey, 2009, 302).

Reflecting upon previous research, it was felt that the maturity and enthusiasm of the students would be strong motivators in the first point above. With regard to the second and third points, the author felt that while additional time would certainly be needed to both learn how to create the online resources and then to deliver and support them, this was a worthwhile investment in creating improved learning resources.

The positive implications for adopting the blended approach are suggested to be many including the point that 'blended learning is, at least potentially, the most transformative and pervasive initiative an institution can undertake' (Niemiec \& Otte, 2010, 118). Reviewing the Duckling project, completed in October 2010, at the University of Leicester which implemented curriculum design and delivery for two course teams, it appeared that of the methods of delivery tried, podcasting was considered to be effective (Duckling Project, 2011). The courses were all at Master's level and involved distance-learning work-based programmes. The key challenges were listed as achieving flexibility to accommodate mobility, increasing engagement, reducing learner isolation and increasing retention. In this project they chose to use e-book readers (Sony PRS-505s) as their mobile devices.

\section{The Implementation of the Study}

An important consideration was whether to base the newly designed course on an internal (to the University of Greenwich) platform or to use an external platform. Another institution has developed a model whereby their MBA programme is hosted on an external platform (Facebook) with access to the course material being free to all. Fees are only incurred when taking exams. It was decided not to take the external platform approach for a number of reasons, including the potential difficulty in retaining sufficient control over access, potential difficulties in dealing with reliability problems and academic integrity and credibility issues. The internal platform route contained potential difficulties, too. The University of Greenwich Business School (UoGBS) transferred from WebCT to Moodle in September 2011. All staff were required to learn to use Moodle and to provide all learning material through the new Moodle platform. This transition needed to go live by the end of September 2011 when the 
new academic year began. Hence, there was a need to redesign the course and learn to use a completely new tool over the summer of 2011.

These complications influenced the decision about what to include in the new course design. Noting the tools used by several others, including the University of Leicester Duckling project, it appeared essential to use:

- Podcasts to either replace or to augment the lectures which were traditionally delivered on a Monday evening from 18.00-19.15. It was intended to use software such as Audacity open source software for the podcast recording.

- A Chat Room (synchronous) and Forum (asynchronous), to replace or to augment the tutorials which traditionally took place on a Monday evening between 19.30 and 21.00. These would be designed to include the use of Wikis for recording joint work.

- $\quad$ A Forum (asynchronous) for discussion about issues of importance to the students. This was situated on the home page of the Course Moodle platform; it could be accessed at any time by the students. It was monitored periodically by the author.

- The elements listed above were accessible to the students at any time by using their UoG Student User ID and password.

The whole proposal was developed through reflection about what was needed and could be provided in a practical way for the students as well as keeping in mind the Good Practice suggestions gleaned from the literature review. Thus it had been planned that podcasts could stand alone as well as augment the lectures. Also it was intended that the Chat Room resource could be flexible enough to incorporate interaction between those who were present in class and those who were unable to attend physically but could join online.

The self-training element was a key challenge in undertaking the project. Joining the University staff as a Visiting Lecturer in autumn 2009 (and a fulltime member of staff in 2010) with no experience of working in the VLE, the need to self-train was very clear. The resource management system at that time was WebCT based and it was relatively easy to 'get by', since tutorial work involved using paper handouts and the lectures needed only a PowerPoint slide set. While these should have been deposited in the WebCT site for student access it was not compulsory. In early 2011 the introduction of Moodle was announced. This required the author and his colleagues to learn to populate their respective Moodle Course shells with the resources needed to provide their students with $24 / 7$ access to their course materials. While training was available, the challenge was considerable and many found the challenge rather daunting.

For this author the challenge involved learning to use a Moodle-based process to create a Course web page. This was a challenge common to all faculty members with responsibilities for a course or programme. Basically there was a need to create a Course Handbook and to upload pdf files of PowerPoint slides for each topic on the programme. Beyond this, the course and programme leaders could decide for themselves what additional resources would be included. 
For the author the additional challenge was learning how to

- record podcasts for each topic of the course to replace/augment lectures

- create Chat Rooms (synchronous) with wiki support

- create Forum facilities( asynchronous) that the students could use for discussion and the tutor could use for announcements

From the author's point of view, the challenge was considerable. While some technical support and training was available, the task was essentially a solitary one. There was much trial and error. A good example of this relates to the podcasting process where file size became a major issue and a compromise was needed. In trying to create podcasts using Audacity software, the author was advised that when creating a "televised lecture including slides" the file size would probably be too large for Moodle to accommodate. A compromise was to create a PowerPoint file with voice over on each slide. In doing this a further complication arose because at that time a Moodle requirement was that uploaded files should be pdf in format. However, pdf files would not support sound at that time and each file containing "PowerPoint plus voice over" was eventually uploaded as a PowerPoint file. This process was followed for each of the eleven subject topics.

This work was carried out during July, August and September 2011. The Course site was ready for use by the first week of October 2011 when the students started the term.

It was proposed to the (Acting) Dean of UoGBS in March 2011, that it would be helpful to ensure that the students had a common technical platform similar to that reported in the Duckling project. Since the Duckling project students encountered limitations in their Sony ereaders, it was proposed that a more flexible portable device was adopted and the iPad2 was proposed by the (Acting) Dean. This device, it was suggested, would ensure that the students could access the course material at their convenience. It was proposed that, through a Wi-Fi connection, the material could be downloaded at will. It would facilitate, as well, the uploading to the portal of the two assignments that the students are required to submit as part of their course requirements.

This proposal was not approved and actioned until late September 2011. The iPad2's were received on $1^{\text {st }}$ October and distributed on $3^{\text {rd }}$ October 2011 at the author's first meeting with the student group. The iPads were distributed to the students free of charge. There was no obligation to return them and they were told that they could use the iPads for anything including recreational games. They were, however, asked to keep a record of the various uses and the Apps that they loaded. They were asked, as well, to share with others the Apps they used and found useful.

The student group comprised nine women and one man. The age range was 30-40. All had jobs with some seniority; some in the Public Sector and some in the Private Sector. As in previous years, all reported being "time poor" having busy jobs with high demands but without fixed hours and a personal life including, in some cases, children. It is probable that 
most would not have been doing the course if it were not the case that it is part of professional accreditation and continuing professional development.

The goal of this project was, therefore, the redesign of a postgraduate Masters degree course at the University of Greenwich using a blended learning approach. A change was proposed from a simple traditional face to face style of teaching to a blended learning approach which would allow the students greater flexibility in their learning. The aim was to redesign the course so that as well as the traditional face to face approach remaining available to students, there would be a number of new online resources such as the Course Guide and Handbook, course material including PowerPoint slides, lecture-based podcasts, chat room tutorials and library resources.

\section{Results and Discussion}

The course structure was designed to combine the use of online tools (podcasts, course handbook and guide, etc) with face-to-face teaching and learning. The online element made available to the students a teaching programme which allowed $24 / 7$ on-line access to the Moodle course management system. In practice, this meant that the students could choose to attend the lectures or keep up/catch up by accessing the course material through the podcast for the relevant topic of the week. The entire group valued this flexibility and during the term several emailed the author to say that they would not be able to 'come to class' because of other demands but that they would be 'attending' the podcast later. The reasons given for non-attendance were mainly work-demand-related, but child care issues and personal and family health problems were also mentioned.

One key question to explore was whether the $24 / 7$ availability of course materials through the Moodle web page was a welcome, learning-enhancing development which increased the students' satisfaction with their course. There was a unanimous positive response in student logs. Whether the students accessed the material as their primary source of information about a topic because they did not attend the lecture or as a backup and reminder to their attendance at the lectures, the continuing availability of the podcast teaching material was very highly valued, according to responses to the final questionnaire.

Another key area of interest was to gain an understanding of whether the creation of podcasts containing a voice-accompanied PowerPoint slide presentation would lead to better use and absorption of learning material in comparison with the traditional 'one lecture per topic' approach. The questionnaire results suggest that the 'better use and absorption' contains two aspects. The first is the realisation that multi-modality learning, in this case reading and listening, is more effective than uni-modality learning. The second aspect is that a podcast can be paused or re-run if some reflection or further thought is needed. These aspects of the blended approach increased the students' satisfaction with their course.

With regard to use of the site by the students, there was a huge variability in the beginning. This could be attributed to having more or less digital literacy. The students had both a new approach to learning (through much more use of the course website) and a new piece of portable technology. Only one student had used an iPad2 before. Within two weeks, however, there was a lot of website 'traffic' and all reported that the portable device was a hit 
("much appreciated") and that the website was easy to access and use. The podcasts were considered helpful as a support for the lectures. There were few comments on the podcasts as a substitute for the lectures, since there was high attendance at most classes.

It was intended that the Chat Rooms would come into use in the third week of term. This did not happen since the group expressed a clear preference for attending lectures and tutorials. A later attempt to use this resource met with resistance and the expressed opinion that a tutorial was preferable because it allowed face-to-face contact both with the tutor and with each other.

Part way through the term a student's off hand comment in the short break between the end of a lecture and the beginning of the tutorial led to the introduction of a new element. She was very daunted about the research dissertation that they were scheduled to start in the following term. Not only was it the first time that she would undertake a research project but she had no practical idea of what she was going to research. The author's urging to come up with a research question had only served to increase her anxiety. The other students echoed her "terror".

Remembering John Dewey's principle of learning 'based on discovery guided by mentoring rather than on the transmission of information' which was referred to in the Boyer Report (1998) and the paper by Streitwieser et al. (2010) the potential usefulness of adopting a Community of Practice (COP) approach was recognised at this point. In practical terms, a suggestion was put to the students that, if they wished, we would put aside the tutorial material (anyway available on-line) and discuss their project ideas instead. Three students took twenty minutes each to put their ideas, however nebulous, to the group. The discussion served to provide emotional support, build confidence, cross-fertilise learning and crystallise ideas. The session was such a success that the three asked if they could bring their developed ideas back the following week for similarly constructive criticism. The author proposed to the group that for the two following weeks the planned lectures and tutorials would be set aside and every student would have the opportunity to present their ideas for discussion since they could catch up on the lecture material at another time. The proposal was accepted and very highly appreciated. Their mobile devices were used during the discussions for the recording of notes and ideas. Later they were used to exchange observations, suggestions and support.

While a correlation cannot be proved, it is interesting to note that the two assignments they subsequently presented, one a Literature Review and the other a Methodology for their proposed dissertation, were considered, anecdotally, by the Moderator (also the Programme Leader) and the External Examiner, to be the best pieces of work that they had seen in many years from students on this course. The group average score for the two assignments $(70.1 \%)$ was more than $5 \%$ higher than in earlier years.

Expressed satisfaction level with the new course format was overwhelmingly positive, as measured by a (Survey Monkey) Questionnaire completed at the end of the course. Despite starting the course as novices in research, the VLE and the use of mobile devices, the group was delighted with the easy availability of the course materials through the course Moodle web page, the revised contents of the materials and their $24 / 7$ availability. They described 
this as a really useful augmentation to the face-to-face contact. Additionally, they were delighted with the mobile device which supported the whole enterprise, feeling that this made the improved materials and resources even more accessible and helpful.

Overall, there were a number of considerations which would influence the use of iPads in future. Word software is not readily available, secondly, there were problems in using Flash Player on an Apple product and thirdly, there is a lack of a USB slot. These three issues are related to decisions made by Apple regarding the configuration of the iPads. By early 2013 these problems had been overcome through the development of Apps and peripheral equipment. However, in future the author would, nonetheless, seriously consider other mobile devices. Since this study was initiated, a considerable number of mobile devices, including tablets, have become available and unit pricing has become a major consideration as the blended learning approach, supported by mobile devices, is made available to students on an increasingly widespread basis.

Finally, it was disappointing to discover that the INDU1008 course was to be discontinued. The materials and course resources are mothballed and remain unused by colleagues. It may be that the materials, such as the podcasts, will be placed in a repository such as YouTube or JORUM.

Overall, there was clear evidence that the students responded to the blended approach in terms of enhanced learning, increased engagement and appreciation.

\section{References}

Boyer. E.L. (1998). Reinventing undergraduate education: a blueprint for America's research universities. Available at: http://naples.cc.sunysb.edu/Pres/boyer.nsf/. (Accessed 19 April 2012).

Duckling project, (2011) University of Leicester. Available at: http://www.le.ac.uk/duckling Accessed 1 April 2012).

Gerbic, P. and Stacey, E. (2009). 'Conclusion'. In Stacey, E. and Gerbic, P. (eds.), Effective Blended Learning Practices: Evidence-Based Perspectives in ICT Facilitated Education. Hershey, PA: Information Science Reference, 298-311.

Niemiec, M., and Otte, G. (2010). 'An Administrator's Guide to the Whys and Hows of Blended Learning'. Journal of Asynchronous Learning Networks, 14(1), 91102.

Partridge, H.; Ponting, D. and McCay, M. (2011). Good Practice Report: Blended Learning. Available at: http://eprints.qut.edu.au/47566/1/47566.pdf (Accessed 17 April 2012).

Streitwieser, B.; Light, G. and Pazos, P. (2010). Entering the Community of Practitioners: A Science Research Workshop Model. Available at:http://www.northwestern.edu/searle/PDF/StreitwieserLightPazos working paper.pdf (Accessed 20 April 2012).

Welker, J. and Berardino, L. (2005). Blended learning: understanding the middle 
ground between traditional classroom and fully online instruction. Journal of Educational Technology Systems, 34(1), 33-55.

\section{Acknowledgements}

Thanks to Dr Doreen Nielson for her help on iPad administration.

\section{Author Biography}

lain Carruthers-Jones joined the University of Greenwich Business School's Department of Human Resources and Organisational Behaviour in 2009 and became a member of the Centre for Innovation, Imagination and Inspiration in 2011. He is interested in both the use of digital technologies in learning and in the challenges of leadership in SME's. 